\title{
UMA LEITURA DO MODERNO CONTO PORTUGUES
}

\author{
MARIA ELIZABETH GRAÇA DE VASCONCELLOS \\ (Professora adjunta de Literatura Portuguesa da Universidade \\ Santa Ursula, RJ, e professora assistente de Literatura Portuguesa \\ da Faculdade de Letras da UFRJ)
}

A presentar um breve panorama do conto português moderno, eis a tarefa que nos coube no debate da tarde de hoje. $O$ que tentaremos mostrar deve ser considerado como conclusōes de estudos feitos quando ministramos o curso "O moderno conto português" na Faculdade de Letras da UFRJ, em 1973, e na Faculdade de Letras da Universidade Santa Úrsula, em 1975. O exame de diversas obras, que revelou analogias a contrastes entre elas, nos possibilitou a fixaçāo de cinco niveis; assim, certos de que nenhuma leitura é inocente, não pretendemos esgotar nesta exposição todas as possibilidades que nos oferece o vasto repertório do conto do século $X X$, em Portugal, "Uma leltura do moderno conto português": els a nossa proposta.

Passemos, pois, ao exame dos cinco níveis.

1. O desajuste social "simplesmente" desvelado.

Consideramos, principalmente, a emergêncla de uma "problemática do tlpo sociológico" 1 e o conto-exemplo é "O "monte' das rosas" de Urbano Tavares Rodrigues, que faz parte de Uma pedrada no charco, obra publicada em 1957.

Se o que caracteriza o romance neo-realista é também a presença da "problemática de tipo sociológico", que terá como cenário preferido as provincias do Ribatejo e do Alentejo - impérios do latifúndlo - poderiamos aqui tentar uma aproximação. Em "O 'monte' das rosas", Urbano Tavares Rodrigues evoca tal espaço, marcando a presença de dois conjuntos: o do grupo explorado e o do indivíduo centralizador. No conjunto 1, os lavradores sāo apresentados como um grupo quase uniforme: quando algum deles assume 
um lugar no proscênlo, é caracterizado como "bicho esquivo", "magro como um vime" ou "encolhido, com medo". Nesse espaço, germina a revolta: "O Alentejo era uma imensa seara de ódio, a crescer sob o sol escaldante. Pensando no destino dessa terrivel messe de raivas surdas e inflamadas, Teresa tinha medo. Nảo por si, mas por todos os inocentes." 2

No espaço 2, o individuo centralizador é desenhado na figura de Relegueirc... que a si próprio se intitulava um "branco grande", em oposiçāo aos comuns mortais, 'os pretos', gente de espinha murcha e escarcela seca." 3 Quanto às reivindicaçōes dos lavradores, assim argumentava: "... uns parvos... que não ganhavam nada com as casmurrices em lhes dando para ali... Liberal, era-o dele, como um senhor antigo, em dia de casamento e de baptizo ou de festa rija no 'monte', quando thes enchia de vinho o bandulho. Mas que ninguém se lembrasse de the fazer frente, de lhe contrariar uma ordem ou de reclamar fosse o que fosse. Oue o senhor ali era ele e mais ninguém." $t$

Circulando entre os dois conjuntos está Teresa. Embora pertencente à burguesia, - como dizia Relegueiro, "sempre era uma pequena de boa familia" 5 - alimentava grande simpatia pelos camponeses: "Quem julgam que sou? E convosco que estou. Acho que devem ser pagos como homens e não como servos. Nāo sei se têm razāo neste caso, nem me importa: seja como for, sou por vocês, que são pobres e orgulhosos." 6

Assim. Teresa é, antes de tudo, um personagem à procura de um espaço: os lavradores não the perdoam o "status" e Relegueiro a classifica de "excêntrica" - atribuição que sugere uma segunda leitura: fora do centro, fora da "velha ordem". E ela, entāo, por tentar conciliar os dois espaços, a vítima do conflito entre o grande proprietário e seus contratados.

O que salientamos como um dos pontos significantes nesta narrativa breve - "O 'monte' das rosas" - é o conflito entre o grupo desfavorecido e o grupo explorador; e, se quiséssemos buscar uma correspondência no campo do romance, lembrariamos de $\mathbf{O}$ trigo e o joio de Fernando Namora e de Vindima de Miguel Torga, em que, na procura de um espaço por parte de alguns personagens, também se desvela o problema social.

2. O fantástlco, uma estratégia de crítica?

Quando falamos, inicialmente, em desajuste social "simplesmente" desvelado, fizêmo-lo com a intençāo de contrapor uma abordagem transparente do problema em oposição a uma outra que lança māo do artificio do fantástico. De fato, utilizando os conceitos de Tzvetan Todorov em Introdução à literatura fantástica, podemos repetir "...o fantástico permite franquear certos limites inacessiveis quando a ele não se recorre." 1 ou ainda ". . a funçāo do sobrenatural é subtrair o texto à ação da lei e com isso mesmo transgredi-la." :

Portanto, o fantástico é utilizado como meio de burlar a censura e se constitui em veiculo de critica aos desconcertos do mundo. Para exemplificar 
tais conceitos, lançamos mão de "A estranha deformação física" de Maria Judite de Carvalho, em Os Idólatras, e de "O jantar do bispo" de Sophia de Mello Breyner Andresen, em Contos exemplares.

No conto de Maria Judite, Ivo, o personagem que, aparentemente, pertencia ao espaço da normalidade, passa para o da anormalidade. por causa de uma "estranha deformação física" que lhe surge: nascem-lhe asas. Impossibilitado de conviver no seu melo social, abandona-o e lança-se ao desconhecido. Seguindo os conceitos de Todorov, podemos dizer que esse conto é uma alegoria: asas têm um outro sentido para além do literal, asas, como simbolos ascensionais 3 , arquétipos de liberdade. E assim, o sujeito da enunciação, o verdadeiro "sábio", fornece ao leitor elementos para uma segunda interpretaçāo do titulo: a estranha deformação "física" seria do personagem-homem o da sociedade?

Continuando pelos caminhos do fantástico, chega a vez de "O Jantar do Bispo" de Sophia de Mello Breyner, em que se nota a oposiçāo entre dois conjuntos: o dos Donos do Mundo (do qual faz parte o Dono da Casa e sua familia) e o dos oprimidos (ao qual pertencem o Pároco e os mendigos). O padre, porque colocava em perigo o equilibrlo da "velha ordem", do "espaço da normalidade", deveria ser transferido para outra aldeia.

Passemos à verificação de como Sophia utilizará, estrategicamente, elementos sobrenaturais como auxiliares para uma critlca social. A narrativa elementar comporta dols tipos de episódios: os que mostram um estado de equilibrio ou de desequllibrio e os que mostram a passagem de um para outro. Com a utilização de um elemento sobrenatural, rompe-se o primeiro equilibrio em "O jantar do bispo": "Mas o Diabo que espreita a ocasião resolve "intervir." \& Com a utilização de uma outra intervenção sobrenatural, rompe-se o desequilibrio mediano e inicia-se a demanda do segundo equilibrio: "E Deus no Céu teve dó daquele Bispo porque ele estava só e perdido e não sabia lutar contra os hábeis discursos dos donos do Mundo." s

Mais uma vez, o sujeito da enunciaçāo configura-se como o revelador da negatividade do contexto social: o conto - que repete a luta de Deus e do Diabo no mundo corrompido ${ }^{6}$ - constitul uma alegoria ou, se quisermos, uma paräbola. E para ratificar a afirmação, vem em nosso auxilio a epigrafe de Contos exemplares, que é a mesma de Cervantes no "Prólogo al lector" em Novelas ejemplares: "Heles dado el nombre de ejemplares, y si bien lo miras no hay ninguna de quien no se pueda sacar un ejemplo."

Portanto, dessa nossa segunda etapa emerge como ponto fundamental a funçāo do fantástico: crítica, feita de manelra estratégica, ao contexto considerado negativo.

3. O movimento de "des-coberta".

Já que falamos em personagem à procura de um espaço, podemos falar também em personagem à procura de um equilibrio. Ora, se o Homem procura o equilibrio em seu meio, verifica que as possibilidades oferecidas pela sociedade estāo todas contidas dentro de um espaço previsível, a fím de 
que o equilíbrio do grupo nāo corra perigo. Assim, ou o Homem se adapta ao esquema dos modelos possiveis - mesmo tendo de se anular - ou sai em busca de uma nova possibilidade, de uma "utopia". de um "não-lugar-marcado".

O primeiro caso pode ser exemplificado com "A Noiva inconsolável" de Marla Judite de Carvalho, em As palavras poupadas. A moça de classe média é dada somente uma opção: casamento. E o seu lugar marcado; é isso que paí, māe, irmāo esperam de Joana. E nela, o desejo de pertencer ao espaço da "normalidade" passa a ser tão forte, que, num movimento de acomodação, depois da morte do noivo, assume a máscara de "noiva inconsolável":

Depois, nessa manhá, lera a noticia no jornal. Vinha o retrato dele, um retrato antigo que ela nāo conhecia. Mas havia tantas coisas que ela nāo conhecia e tantas pessoas... Pessoas a falar e ela a ouvi-las e a responder, a ter opiniōes. Quais? Que teria dito? $O$ seu atual pensamento flutuava levemente numa atmosfera mansa, batia ao de leve as asas, aflorava as coisas. Toda a angústia desapareceu. Já não receava nada, já não ia recordar todas as manhās a pensar que talvez tudo fosse terminar antes da noite. Sentia essa calma no rosto que não via, nas mãos quietas, na voz que lhe saía direita, quase rigida. A serenidade que ele lhe negara! Apetecia-lhe sorrir mesmo sem estar alegre, sorrir precisamente porque estava triste. Sorrir à mãe quando ela entrasse com os trapos pretos que nunca mais havia de despir, sorrir ao pai, ao irmão, às amigas que tinham acabado de descer a escada, sorrir a toda a gente. Era de súbito outra pessoa. A noiva inconsolável do homem que morrera. 1

Estabelecem-se, portanto, dois momentos no conto: antes da morte do noivo, quando Joana, individuo, caracterizada pela insegurança, procura o seu lugar marcado, e depois da morte do noivo, quando, já um tipo, passa a pertencer ao mesmo mundo das amigas. da mãe, do pai, do irmāo, caracterizando-se pela segurança que o lugar de "noiva inconsolável do homem que morrera" Ihe confere. Portanto, se na série individual houve uma degradação Joana passa a agir segundo as regras do PARECER - na série social verifica-se um aperfeiçoamento: o grupo, exercendo sua força sobre o individuo, fá-lo ocupar o seu lugar no esquema dos modelos possiveis.

Passemos ao segundo caso: inadaptado ao "status-quo", o Homem sai à procura de "outro lugar" ou do "paraíso perdido". No conto "A viagem" de Sophia de Mello Breyner, Homem e Mulher - personagens-signum - buscam - lugar perfeito, no tempo simbólico de um dia. A trajetória, marcada por encontros e desencontros, por descobertas e perdas, conduz finalmente ao abismo:

Então tentou descer pela própria vertente do abismo. Agarrando-se a ervas e raizes deixou-se escorregar ao longo do pre- 
clpicio. Mas os seus pés năo encontravam nenhum apoio onde pudessem firmar-se. Pois a vertente descia a pique, era uma parede lisa de pedra nua.

- Tenho de voltar para o carreiro - pensou a mulher - e tenho de procurar mais adiante uma passagem.

$E$, agarrada a ervas e raizes, içou-se para o carreiro.

Mas o carreiro tinha desaparecido. Agora havia apenas um estreito rebordo onde ela não cabia, onde nem os seus pés cabiam. Um rebordo sem saída. Aí ficou, de lado, com os pés um em frente do outro como as figuras dos desenhos do Egito, com - lado direito do seu corpo colado à pedra da arriba o o lado esquerdo já banhado pela respiração fria e rouca do abismo. Sentia que as ervas e as raizes a que se segurava cediam lentamente com o peso do seu corpo. Compreendia que agora era ela que ia cair no abismo. Viu que, quando as raizes se rompessem, nāo se poderia agarrar a nada, nem mesmo a si própria. Pois era ela própria o que ela agora ia perder.

Compreendeu que the restavam somente alguns momentos.

Então virou a cara para o outro lado do abismo. Tentou ver através da escuridão. Mas só se vía escurldão. Ela, porém, pensou:

- Do outro lado do abismo está com certeza alguém.

E começou a chamar. 2

Em 1963. Herberto Helder publica Os passos em volta em que se encontra "Descobrimento", dedicado à Sophia de Mello Breyner. Nesse conto, o "homem" é também um personagem-signum, num tempo de viagem, num tempo de procura, num tempo de des-coberta. A rua circular, que percorre multas vezes e que o leva sempre ao mesmo lugar, instaura o tema do círculo:

E quem pode dizer que, à noite, no estrangeiro, depois de duas cervejas no estômago completamente vazio, a rua circular não era ainda mais circular? Ele começava por aquela praça onde havia um anúncio luminoso dos automóveis "Packard" e acabava na mesma praça, com o rosto ansioso voltado para as mesmas letras que acendiam em vermelho no meio da névoa: P-A-C.K-A.B.D. Pode-se recomeçar cem vezes a mesma frase musical. Comprova-se cem vezes o resultado de uma experiência fisica ou quimica. $E$ ainda se verlfica que 6 do abismo que vem a ressurreição. Percorria a sua dúvida (agora já não pensava na inocência e na malícia para chegar sempre à praça) e de novo duvidava. Muitas vezes ainda entrou na cervejaria que ficava próxima. Dizem que Goethe escreveu vérias vezes algung dos seus melhores poemas. Leonardo era mortalmente paciente em 
frente das cores. $\mathrm{E}$ o que sabemos dos outros, dos mais antigos? Tudo é eternamente recomeçado. Não se sabe o que acharam. Acharam alguma coisa, os antigos, os modernos?

O que esse homem procurava e achou não é exemplo. E embora toda a poesia seja uma proposta ou uma solução moral, nós, os homens desta nação, só podemos imaginar as alegrias e as dores desse homem estrangeiro, ao frio e à névoa, na grande solidão dessa rua circular que talvez não exista em Antuérpia, nem em outra qualquer cidade deste tão grande, tão grande mundo.

Mas quem pode confiar em nós que somos desta terra que, por isso, tão mal a conhecemos? 3

Tanto em "A viagem", quanto em "Descobrimento", o conflito é abandonado em suspenso: o Homem alcançará, algum dia, o paraiso perdido? 0 Honiem virá, ainda, a "Jes-cobrir-se"? do "abismo" e da "rua circular" nas. cerá a selvaçāo?

4. O tema amor: Jesestruturação do modelo tradicional.

As mültiplas e incessantes modificaçōes que caracterizam o viver do século $X X$ também se farāo sentir no tratamento do tema amor na literatura. Ou será mostrada a impossibilidade de comunicaçāo - como acontece em "Duas pessoas" de Herberto Helder - ou a constante procura sempre frustrada - "A impossivel evasão" de U. Tavares Rodrigues - ou, ainda, de modo irōnico, a desestruturação do modelo mitico tradicional.

Considerando que o mito de Tristāo e Isolda funciona como modelo da literatura amorosa do ocidente, chegamos a estabelecer determinados conceitos que sāo repetidos em diferentes épocas: amor oculto, amor impossivel, amor associado à morte, amor associado à idéia de Deus, amor fruto do acaso. 1 Ora, há narrativas que atestam a ruptura de tal modelo, como é o caso de "Um homem de barbas" de Manuel de Lima.

Alguns episódios desse conto sāo paródias de episódios homólogos de narrativas da série tradicional. O triāngulo amoroso - repetido nas figuras de Natália, Valeriano e Montalvão - é desestruturado através de estranhamentos introduzidos na caracterização de cada um dos membros que, assim, rompem com a série tradicional a que pertenceriam.

Natália apaixona-se por Valeriano por causa das barbas deste; quando o amante desaparece, convence o marido, Montalvão, a emagrecer e a deixar crescer as barbas. Substitui o amante por um marido "reformado". Ao contrário das heroinas românticas, que rezam para que o amado volte do duelo são e salvo, Natália se lembra de Deus quando suspeita que pode ficar sem marido e sem amante.

Em relação a Valeriano, dois momentos podem ser lembrados como sig. nificativos para sua "caracterizaçăo às avessas": o duelo, quando, arrepiado, treme a ponto de parecer duas pessoas e tem de ser firmado ao solo por 
melo de estacas, e o encontro noturno com Natália, quando, surpreendido por Montalvāo, é rodado 366 vezes pelas barbas e desaparece nos ares, e para sempre. Este heról não volta...

Montalvăo, o marido posteriormente metamorfoseado a pedido da esposa, assume o lugar do amante e assiste-se a um "final feliz"... temporário.

No nivel da narraçāo, a ruptura é feita através da ironia. $\mathrm{Na}$ ida para 0 duelo, por exemplo, quem filosofa é a mula:

A de Montalvāo seguia normal: nem cansada nem folgada, indiferente a tudo como o cavaleiro. Submersa em problemas de grande complexidade, vedados ao raciocinio humano, parecia não pressentir Montalvāo. Como se fosse sozinha, caminhava por cima de muros fazendo verdadelros prodígios de equilíbrio. Quando perdia o flo dos pensamentos, parava, só continuando a andar depois do guia a convencer, por intermédlo do cajado, que a pensar morreu um burro. Então como que apanhando repentinamente a seqüêncla dos raciocínios, continuava satisfeita a marcha, zurrando discretamente. 2

Com isso, o autor denuncia o código dos aforismos que, nas narrativas tradicionais, encerram ensinamentos de acordo com a ideologla dominante. 3

Já que falamos no mito do amor, podemos citar o conto "Teorema" de Herberto Helder, onde se nota o desvelamento de espaços até entāo esquecidos. $\mathrm{O}$ assassinato de Inês, sempre aproveitado para alimentar a ideologia dominante, é agora visto sob uma outra ótica: o assassino conta a sua morte. e perpassa por toda a narrativa um tom de crítica às tradiçōes da "velha ordem".

5. O escritor, um artesão da linguagem?

Aqui, destacamos "Conto contado" de Almeida Faria em que, através de uma linguagem polifônica ${ }^{1}$, apresenta-se o choque de dois conjuntos: o da liberdade - que inclul a menina e o louco, e tem como pano de fundo espaços marinhos - e o da mascarada social. Para a sociedade, como já vimos, cada personagem tem o seu lugar marcado e, sendo assim, menina e louco não podem estar juntos, pois tal convivência colocaria em perigo o equilíbrio do grupo. E vem a separação. Tempos depois, a menina, já adulta, consciente da violência de que fora vítima, resolve se vingar através da escritura. A linguagem de Almeida Faria reinventa um mundo: a quebra da sintaxe tradicional, as palavras compostas de maneira inusual, os neologismos, as repetiçōes, as aliteraçōes dão a medida das novas relaçōes que o autor estabelece:

Mas tudo era outro, menina entendla, ele só sonhara um mundo distinto, não o dos adultos que, alientão, tão alienados, viviam-morriam, mas quando cresceu desquiz ser assim, como eles morridos, de modo que fol para muito longe, para multo 
perto das margens da vida, onde não havia adultosantlgos, só novosmeninos, como ela, menina, tramontava o sol, definal do dia, andavam no campo, ele ia apontando o leontopódio, e o alcaçuz, o alegracampo, e os peroscasanova e os lambelhosdedos, a aböboramenina, menininhazinha, a menina olhava do homem a face: alvaface-clarosolhos, luminosobrilho e quente olhar, se os olhos são alma, ou imagem dela, a dele era bela, era almabreve, porque breve-breve o dia já era, era já partida, tudo lufalufa, tudo rodaviva, na selva selvagem de horários a deveres de gente deslivre, a menina olhava a cara da gente: tudo faceescura, tudo olhosnoite, tudo malascaras, fechadas de medo, tudo sorrisinhos, despedidas frias, beijamão e - pé, essa gente toda, os Teria-sido e mais os Seria, os Foram, Serāo, e os Há-de-ser, Havia-de-ser, e o Raicosparta, de triste, a menina tornou-se zangada, jurava vingar-se, e mais quando soube que ele não comera depois desse verão, e ela vingou-se, escreveucontou estórias que os tais detestavam, temiodiavam, e assim era bom e assim estava certo, assim como esta, esta estóriaconto que termino aqui, louvadibendito o conto finito, benditilouvado o CONTO CANTADO. :

E poderiamos finalizar com pergunta que em si já encerra uma resposta: "a palavra, uma estratégia de crítica?"

Algumas palavras como conclusão.

Como dissemos no inicio, no breve espaço de tempo que nos coube, tivemos como objetivo apresentar apenas um dos caminhos possiveis para a leitura do moderno conto português. Entretanto, não poderiamos finalizar esse estudo sem referenciar os contos de Miguel Torga. Em Contos da montanha e Novos contos da montanha prevalece o princípio básico de oposição "código natural x código social": o Homem, com sua verdade biológica, tem o seu espaço privilegiado, ao lado do mundo animal e do vegetal. Aqui não se verifica a procura de um espaço ou de um equilibrio, mas, sim, a defesa de um espaço já considerado perfeito - "montanha" como "eixo do mundo" - contra qualquer intromissão, quer do código ético - "Mariana" - quer do código religioso - "O senhor" - quer do código social - "Fronteira" pois "A vida estã acima das desgraças e dos códigos". 3

\section{NOTAS E REFERENCIAS BIBLIOGRAFICAS:}

1. O desajuste social "simplesmente" descelado.

1 Empregumos as conceitos formulados por Fernundo Mendonça en 0 romnnce portugués contemporânco. Facuidade de Filosolla, Cténcias e Letras de Assis, 1966.

2 RODRIGUES. Urbano Tavares. "O 'monte' das rosas". In: Uma pedrada no charco. 2." ed. Bertrand, 1959, p. 184.

3 Id. ibid., p. 203.

4 Id. ibid., p. 210. 
5 Id. ibid., p. 214.

6 Id. ibid., p. 214.

2. O fantástico, uma estratégía de crftica?

1 TODOROv. Tzvetan. Introduçăo à literatura fantristlea. Sāo Paulo, Perspectiva, 1975, p. 167.

2 Id. ibid., p. 168.

3 Cr. DURAND, G. Les structures anthropologiques de l'imaginaire. Paris, Bordas, 1972, p. $138 \cdot 162$.

4 ANDRESEN, Sophia de Mello Breyner. "O jantar do bispo". In: Contoa exemplares. 3.a ed. Lisboa, Portugália, 1970, p. 30.

5 Id. ibid., p. 43.

3. O movimento de "des-coberta".

1 CARvaino, Maria Judite de. "A noiva inconsolável". In: As palavras poupadas. 2. ed. Lisboa, Arcitia, s/d., p. 136-136.

2 ANDRESEN, Sophin de Mello Brcyner. "A viagem". In: Contos exemplnres. 3." ed. Lisboa, Portugália, 1970, p. 109-111.

3 HELDER, Herberto. "Descobrimento". In. Os passos em volta. 2." ed. Lisbou, Portugúlia, 1964, p. 79.

4. O tema amor: desestruturação do modelo tradicional.

1 CF. VASCONCELLOS, Marin Elizabeth Graça de. 0 homem no mentido latente do milo do amor-paixão. Dissertaçăo de Mestrado. Rlo de Janeiro, Faculdade do Letras da UFRJ, 1972.

2 LIMA, Manuel de. "Um homem de bnrbas". In. Antologia de vanguarda. Lishon, Afrodite, s/d., p. 204.

3 Num trabalho mais extenso, poderinmos, usundo os conceitos de Affonso Romano de Sant'Anna, mostrar que "Um homem de barbas" constitui uma narrativa de estrutura complexa.

5. O escritor, um artesăo dn Inguagetn?

1 Usamos a expressāo de Fernando Mendonça, op. cit.. p. 142.

2 FARIA. Almeida. "Conto contido". Cadernos braxileiros. Rio de Janciro, 54: 68-72, jul./ago., 1969, p. 72.

3 TORGA, sliwuel. "Fronteira". In. Novos contos de montanha. 5.2 ed. Coimbra, D. 28.

\section{B I B L I O G R A F I A}

A. Alguma teciria.

1. aNalise estrutural da Narrativa. Petrópolis, Vozes, 1971.

2. AREAS, Vilma. Itinerário de sels exemplos: Contos exemplares. Cadernos braslielros. Rio de Janairo, 54: 77-83, Jul/ago., 1969.

3. BACHELARD, Gaston. A poética do espaço. Rlo de Janciro, Eldorado, s/d.

4. BELLEMIN-NOEL, Jean. Notes sur le (antastique (textes de Theophile Gautier). LItérature. Paris, 8: 3.23, déc., 1972.

5. BERARDINELLI, Cleonice. Um conto fantástico, Colóqulo/Letras. Lisboa, 27: 40-43, set., 1975.

6. ELTADE, Mircea. Mito e realldade. Såo Paulo, Perspectiva, 1972.

7. MENDILOW, A.A. O tempo e romance. Porto Alegre, Globo, 1972.

8. SANT'ANNA, A. Romano de. A narrativa de estrutura simples e de estrutura complexa. Revista de Cultura Vozes. Petrópolis, 4: 21-30, mai., 1972. 
9. SILVEIRA, Jorge Fernandes da e AREAS, Vilms. Análise de Novos Contos da Montanha. Cademos da PUC. Rlo de Janeiro, 9: 51-62, mai., 1972.

10 TODOROV, Tzvetan. Introduçăo a literatura fantástica. Săo Paulo, Perspectiva, 1975.

11. VASCONCELLOS, Maria Elizabeth Graça de. O lıomem no sentido latente do mito do smor-paixão. Dissertação de Mestrado. Rio de Janeiro, Faculdade de Letras da UFRJ, 1972.

12. VAX, Loius. A arte e a literatura fantisticas. Ijsbos, Arcadis, 1972.

ALGUMAS OBRAS EM QUE SE FUNDAMENTA A PROPOSTA DE LEITURA:

ANDRESEN, Sophin de Mello Hreyner. Contos exemplares. 3.a ed. Lisboa, Partugálin, 1970.

CARVALHO. Marja Judite de. As palarras poupadas. 2." ed. Lisboa, Arcidia, 1961.

Os idólatras. Lisboa, Prelo. 1969.

FARIA, Almeidn. Conto contadu. Cadernos brasileirọs. Rio de Janeiro, 54 : 68-72. jul/ago., 1969.

Helder, Herberto. Os passos em volta. 2." ed, Lisbon, Portugália, 1964.

LIMA, Manuel de. Um homem de barbas. In: Antologia de vanguarda. Lisboa, Afrodite $s / d$.

LINHAHES, Temistocles (org. ch). Antologin do moderno conto português. Rio de Janeiro, Civilizaçüo Brusileirs, 1968.

ANTOlogia do CONTo Fantástico portugues. Revisāo, notas e introduçüo de E.M. de Melo c Castro. Lisbon, Afrodite. 1974.

NEVES, Jō̄o Alves das (org. de). Contistas portuguesen modernos. Snmambaia. s/d.

RODRIGUES, Urbano Tavares. Uma pedrada no charco. 2.* ed. Lisboa, Bertrand, 1959.

TORgA, Miruel. Contos da montanha. Rio de Janciro, Pongetti, 1955.

Novos contos da montanha. 5.: ed. Coimbra, 1967.

\section{TEXTOS}

1. O desajuste sacial "simplesmente" desvelado.

2. O fantistico, uma estratégia de crítica?

"O primeiro foi um negro americkno, humilde lnvador de nutomóveis numa bomba da estrada vicinal, alkures para o sul, que, naturalmente. lincharam e a histórja ficou nor uí. O sezundo. uma espécic de louco visionário que apareceu um dia numa aldeia oriental onde o tempo dir-se-ia ter parado hí séculog. Um homem frácil, de longas cabelos lisos, pẻs descalços e camisola preta, que gritava coisas a que ninsuém onsava dar atenção. A sua viưa também não foi longn, era normal. Seguiram-se outros, quantos? Mas sempre em paises distantes. en vilas e aldeias de nomes dif́ccis, mujto isperos, que nenhum mapa se di so trabalho de situar. No desconhecido, partanto".

CARVAlHo, Marin Judite de. A estranba deformação física. In.: Os idólatras. Lisboa, Prelo, 1959, p. 125.

"E depois. um dia, essa coisa estranha e inominivel aproximou-se sem ninguém dar por elu, nem mesmo o próprio interessado, reonteceu ali mesmo, numa cidnde pequena mas conhecida, com passado, com bistória. Tinha lojas de modus, teatro, museu, dois cinemas, vários restaurantes, alguns hotéis um dos quais luxuoso. Uma cidade que, para mais. licava à beira não de uma estrada vicinal mas de uma auto-estrada turística que se dirixia para o sul, para o sol, para o mar".

Id., ibid., p. 126.

3. O movimento de "des-coberta"

Depois nessa manhã, lera a noticia no jornal. Vinba o retrato dele, um retrato antiso que ela nāo conhecia. Mas havia tantas coisas que ela não conhecia e tantas pessons... Pessons a falar e ela a ouvf-los e a reconbecer, a ter opiniōes. Quais ? Que 
teria dito 7 o seu ntual pensamento flutuava levemente numa atmosfera mansa, batin ao de leve as agag, aflorava ng coisag. Toda a angúbtia degaparecera. Jí nh̆o recenva nada, jú não ia recordar a todas a manhäs a pensar que talvez tudo fosse terminar antes da noite. Sentis essa calma no rosto que não via, nas măos quiatas, na voz que lhe safa direita, quase rfgida. A serenidade que ele the negaral Apetecia-lhe sorrir mesmo bem estar alegre, Borrir precisamente porque estavn tribte. (Sorrir ù māe quando ela entrasse com os trapos pretos que nunca mais bavin de despir, sorrir ao pai, ao irmño, is amigas que tinham acabado de descer a cscada, sorrir a coda a kente). Era de súbito outra pessoa. A noiva inconsolável do hamem que morrera.

Carvalho, Maria Judite de. A noiva inconsolícl. In. As palavras, poupadas, p. 135-136.

Entāo tentou descer pela própria vertente do abismo. Agarrando-se a ervas e rafzes deixou-se escorregar ao longo do precipfcio. Mas os scus pés nūo encontravam nenhum apoio onde pudiessem firnar-se. Pois a vertente descir a pique, era uma parede lisa de pedra nua.

- Tenho de voltar para o carrciro - pensou a mulher - e tenho de procurar mais adinnte uma pagsagem.

E, ngarraln a crvas e ruizes, içou-se para o carreiro.

Mas o carreiro tinka desnparecido. Agora havia apenas um estreito rebordo onde ela näo cabiu, onde nem os seus pés cabiam. Um reborda sem saida. Á ficou, de lado, com os pés um $\mathrm{cm}$ frente do outro como ns figuras dos desenhos do Egito, com o lado direito do seu corpo coludo ì pedra da arribu e o lado esquerdo jü banhado pela respiraçüo fria e rouca do abismo. Sentia que as ervas e as rázes a que se seguruva cediam lentamente com o peso do seu corpo. Compreendia que agora era ela que ia cair no nbismo. Viu que, quando as rúzes be rompessem, dāo se poderia agarrar a nada, nem mesmo a si própria. Pois era ela própria o que ela agara in perder.

Compreendea que the restavam somente alguns momentos.

Então virus a carn para a outro lado do abismo. Tentou ver através da escurldäo. Mas só вe vin escuridāo. Ela, porém, pensou:

- Do outro lado do abismo está com certeza alguém.

$\mathrm{E}$ começou a chamar.

ANDRESEN, Sophin de Mello Breyner, A vingem. In.:

Contos exemplares. 3," ed. Lisbon, Portugálin, 1970. p. 109-111.

E quem pode dizer que, ì noite, no estrangeiro, depols de duas cervejas no estomaxo completamente vazio, a rua circular nüo era ainda majs circular çava por equeln praça onde havia um anúnclo luminoso dos automóvels Packard o acabava na mesma praç, com o rosto ansjoso voltado para as mesmas letras quo acendiam em vermelho no meio da névoa: P-A-C-K-A-K-D. Pode-se recomeçar cem vezes a mesma frase musical. Comprova-Be cem vezes o resultado de uma experiência física ou química. E ainda se veriflica que é do abismo que vem a ressurrciçāo. Percorria a sua dúvida (agora já não pensava na inocéncin e na mallcia para chegar sempre a praca) e de novo duvidava. Muitas vezes ainda entrou na cervejaria que fieava próxima. Dizem que Goethe escreveu várlas vezes algung dos beus melhores poemns. Leonardo era mortalmente paciente em trente das cores. $E$ o que sabsmos dos outros, dos mais antigos $t$ Tudo é eternamente recomeçado. Nüo se sabe o que acharam. Acharam alkuma coisu, os antikos, os modernos?

0 que cssc homem procurava o achou não é exemplo. E embora toda a poesia beja uma projosta ou uma solıçăo moral, nós, os homeny destu nagāo, só podemos imaginur as alegrias e ns dores desse homem estrangeiro. no frí e à névoa, na grande solidāo dessa run cireular que talvez exista em Antuérpia, nem em outra qualquer cidade deste tāo krande, tüo srande mundo.

Mas quem pode confiar em nús que somos desta terra que, por isso, tāo mal a conhecemas?

HELDER, Herberto. Descobrimento. In.: Os passos em

volta. 2." ed. Lisboa, Portugália, 1964, p. 79.

1.4. O tema amor: desestruturaçāo do modelo tradicional. 
"Montalvão nāo se sentin muito bem. Morrer num sitio tāo sombrio, nāo era o seu Ideal. A morrer, gostaria que fosse num incèndio e depois ir para o inferno continuar a vida no melo do foco. eternamente.

Valeriano, esse, arrepiado, tremia a ponto de parecer duns pessons. Se na altura de Montalvāo apontar sobre a sua carcaça esquia continuasse em taís tremuras, 86 por acaso atingiria a alvo. Entīo os gordos vendo o perigo que umeagava Montalvăo e portanto também as suas vinganças subjetivas, protestaram junto dos magros. Estes, espíritos práticos c decidiujos, resolveram o caso imediatamente firmando Valeriano no solo por melo de estacas.

E o momento chegou, enfim, solene !"

L:MA. Manuel de. Um homem de barbas. In: Antologia de ranguarda. Lisboa, Afrodite, s.d., p. 207-208.

Devido no estado te excitaçio de Valeriano, o duclo nūo pôde seguir as praxes convencionais. Combinou-se entüo o sexuinte: Montalvão teria de caminhar um certo número de passos no fim dos quals se devia voltar e desfechar a pistola sobre Valeriano, que com a cabeça torcida para trás aguardaria o sinal que era Montalvāo dizer: "ja pode".

Assim aconteceu. "Os resultados á gue foram inteiramente diferentes do que se esperava.

Dois estampidos quase no mesmo tempo quebravam o silencio dn madrugada e quatro homens enfam por terra soltnndo sritos lancinnntes.

Eram os magros e os xordos que estrebuchavam no chāo, feridos de morte. As balas tinham-se encontrado no percurso e com n violência do cmbate estilhaçaramse etingindo os quntro inimigos que ao fim de dois minutos depois de lançarem urros de raiva e dor juntamente com pragas krosseiras, deixavam de existiz".

Id., ibid., p. 209

"A de Montriliäo seguin normal: nem cansacia nem folgada, indiferente a tudo como o cnvaleiro. Submersa em problemas de grande complexidade, vedados no raciocinio humano, parecin nāo pressentir Montalvão. Como se fosse sozinhn, caminhлул por cima de muros fnzendo verdadelros prodigios de equilíbrio. Quando perdia o lio dos pensamentos, parava, 86 continuando a andar depois do guia a convencer. por intermedio do cajado. que a pensar morreu um burro. Entāo como que apanbando rejentinamente a seqúcinciz dos raciocinios, continuava satisfeita n mareha, zurrundo discretamente-

$$
\text { 1d., ibid., p. } 204
$$

1.5. O escritor, um nrtesão da linguagem?

Mas tudo era outro, menina cntencila, ele só sonhara um rnundo distinto. não o dos adultos que. alientäo, täo alienados, viviam-morriam, mas quando cresceu desquiz ser assin. como eles morridos, de modo que fol para muito longe, para muito perto das margens da vida, onde nīo havia adultosantigos, só novosmeninos, como ela, menina, tramontava o sol. definal do dia. andaram no campo, ele ia apontando o leontop6dio, e o alcaçuz, o alegracampo, e os péroscasnnova e os lembelhosdedos, ab aboramenina, menininhazinha, a menina olhava do homem a face: alvaface-clarorolhos, Juminosobrilho e quente olbar, se os olhos sīo alma, ou imagem dela, a dele era bela. era almabreve, porque breve-breve o dia já cra, era já partida, tudo lufalufa, tudo rodaviva, na selva selvacem de horäios e deveres de gente deslivre, a menina olhava a carn da gente: tudo faceescura, tudo olhosnoite, tudo malascarayfechadas de medo. tudo sorrisinhos, despedidas frias, beijamäo e - pé essa pente toda, os Teria-sicio e mas os Seria, os Fornm, Serio, e os Hí-de-ser, Havia-de-ser. - O Raicosparta, de triste, a menina tornou-se zangada, jurava vingar-se, e mais quando soube que ele nïo comera depois desse verāo, e ela vingou-se, escreveucontou estóriag que os tais detestavam. temiodiavam, e assim era bom e assim estava certo, ausim como esta. esta estóriacanto que termino aqui, louvadibendito o conto finito. benditilouvado o CONTO CANTADO.

FARIA, Almeida. Conto antado. Cadernos brasileiros. Rio de Janeiro, 64: 68-72, jul./ago., 1969, p. 72. 